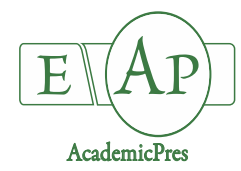

Cheng S et al. $(2020)$
Notulae Botanicae Horti Agrobotanici Cluj-Napoca 48(1):102-115
DOI: $10.15835 /$ nbha48111560
Research Article

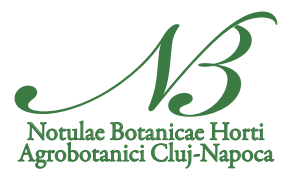

\title{
Characterization and expression analysis of four members genes of flavanone 3-hydroxylase families from Chamaemelum nobile
}

\author{
Shuiyuan $\mathrm{CHENG}^{1}$, Qiling SONG ${ }^{2}$, Tian $\mathrm{YU}^{3}$, Xiaomeng LIU², \\ Lanlan WANG ${ }^{2}$, Dun $\mathrm{MAO}^{2}$, Weiwei $\mathrm{ZHANG}^{2 *}$, Feng XU⿱乛龰 \\ ${ }^{1}$ Wuhan Polytechnic University, National R\&D for Se-rich Agricultural Products Processing, Wuhan, 430023, \\ China;s_y_cheng@sina.com \\ ${ }^{2}$ Yangtze University, College of Horticulture and Gardening, Jingzhou 434025, China; song70@126.com; liuxm925@163.com; \\ wangll30@126.com; maodun1994@163.com;wwzhangchn@163.com (*corresponding author) \\ xufeng198@126.com (*orresponding author) \\ ${ }^{3}$ Serun Health Industry Group, Enshi, 445000,China; ytcau@163.com
}

\begin{abstract}
Chamaemelum nobile is a traditional Chinese herbal medicine, whose secondary metabolites used in the pharmacology of Chinese medicine. Among them, the flavonoids have great research value. Flavanone 3hydroxylase $(\mathrm{F} 3 \mathrm{H})$ is one of the core enzymes in the early steps of flavonoid biosynthesis. This study aimed to elucidate the structures, functions, and expression levels of $F 3 H$ families from C. nobile. Four members of the $\mathrm{F} 3 \mathrm{H}$ family were screened from $\mathrm{C}$. nobile transcriptome data and performed bioinformatics analysis. Results showed that $\mathrm{CnF} 3 \mathrm{H} 1 \sim 4$ had a high similarity with the other $\mathrm{F} 3 \mathrm{H}$ plants, and all genes contained two conserved isopenicillin $\mathrm{N}$ synthase-like and oxoglutarate/iron-dependent dioxygenase domains. Further analysis revealed that the four $\mathrm{CnF} 3 \mathrm{H}$ proteins contained some differences in binding sites. The results of secondary and 3-D structures displayed that the composition and proportion of the four $\mathrm{CnF} 3 \mathrm{H}$ secondary structures were basically the same, and their $3 \mathrm{D}$ structures were consistent with the secondary structures. The phylogenetic tree displayed that $\mathrm{CnF} 3 \mathrm{H} 2, \mathrm{CnF} 3 \mathrm{H} 3$, and $\mathrm{CnF} 3 \mathrm{H} 4$ were grouped with Asteraceae. The expression patterns of $\mathrm{CnF} 3 \mathrm{Hs}$ in the roots, stems, leaves, and flowers of $\mathrm{C}$. nobile were evaluated using the value of RPKM. The results indicated that $\mathrm{CnF} 3 \mathrm{H} s$ had significant difference in the expression of different tissues. Especially, $\mathrm{CnF} 3 \mathrm{H} 1 \sim 3$ and $\mathrm{CnF} 3 \mathrm{H} 4$ had the highest expression levels in the flowers and roots, respectively. Hence, $\mathrm{CnF} 3 \mathrm{Hs}$ played a significant role in the flavonoid metabolism.
\end{abstract}

Keywords: bioinformatics analysis; Chamaemelum nobile; expression pattern; $F 3 H$ families; flavonoids

\section{Introduction}

Chamaemelum nobile is a perennial herb from the Asteraceae family, which is native to southwestern Europe, spread all over Europe, and distributed in southwestern Asia (Ma et al., 2007). C. nobile is a traditional Chinese herbal medicine, whose secondary metabolites used in the pharmacology of Chinese medicine mainly 
include ester volatile oil with calming nerve (Melegari et al., 1988), flavonoids with anti-inflammatory activity (Achterrath-Tuckermann et al., 1980), and sesquiterpene lactone with antibacterial activity (Farhoudi, 2013). In addition the medicinal value of $C$. nobile, its extracts are widely used in formulations of cosmetics, shampoos, hair dyes, and other supplies (Jaziri et al., 1999). Previous scientists have distilled volatile oils from the flowers of C. nobile, but only 0.4\%-1.5\% (dry weight) (Jaziri et al., 1999; Carnat et al., 2004). A few sesquiterpenoids have been isolated and identified from C. nobile, such as $\alpha$-bisabolol, (E)- $\beta$-farnesene, terpene alcohol, and chamazulene (Irmisch et al., 2012; Newall et al., 1996; Schilcher et al., 2005). Only a few genes have been cloned and analyzed, such as 3-hydroxy-3-methyl-glutaryl-CoA reductase (Meng et al., 2016), farnesyl diphosphate synthase (Su et al., 2015), phosphomevalonate kinase gene (Yan et al., 2016), and mevalonate kinase gene (Meng et al., 2016). However, the genes of the flavonoid metabolic pathway are rarely reported in C. nobile.

Flavonoids are important secondary metabolites of plants, which are often bound in vegetables, fruits, beans, nuts, and other plants (Cheng et al., 2018). It can be divided into flavonols, dihydroflavonols, flavones, flavanones, flavanols, anthocyanins, isoflavones, and chalcones depending on the structure (Zhao et al., 2010). Flavonoids are natural antioxidants with anti-aging effects because of their ability to scavenge free radicals (Dooner et al., 1991; Taylor and Grotewold, 2005). It also has the function of protecting the heart (Middleton et al., 2000; Peer et al., 2004), protecting the plants from ultraviolet radiation (Li et al., 1993), and affecting the fertility of plants ( Meer et al., 1992).

Flavanone 3-hydroxylase ( $\mathrm{F} 3 \mathrm{H})$ is a non-heme iron enzyme, which is an oxidized glutarate-dependent oxygenase and mainly relies on $\mathrm{Fe}^{2+}$, oxygen, and 2-ketoglutaric acid to work (Charrier et al., 1995). F3H catalyzes flavanone to yield dihydroflavonol, which is one of the important enzymes in the early stage of flavonoid biosynthesis (Deboo et al., 1995) (Figure 1). Therefore, the expression of $F 3 H$ gene can affect flavonoid content in plants, which may change the depth and types of colors (Elomaa et al., 1993). Until now, the $\mathrm{F} 3 \mathrm{H}$ genes in some plants have been cloned, and their functions have been described in detail (Fan et al., 2014; Hu et al., 2014; Shen et al., 2016). F3H gene is expressed in plant roots, stems, leaves, and flowers (Huang et al., 2013; Kumar et al., 2015). F3H gene can affect all parts of plant coloring, because it regulates the synthesis of flavonoids in plants, while the structure of flavonoid is susceptible to the environment of the vacuole, ambient light, and temperature (Elomaa et al., 1993). For example, it could affect the color of strawberry (Jiang et al., 2013) and raspberry fruits (Lee et al., 2009), Lycoris radiata flowers (Huang et al., 2013), and Reaumuria trigyna leaves (Zhang et al., 2014). F3H gene can affect the growth and development of plants, because most insect-pollinated plants generally have attractive and colorful petals (Zhao et al., 2015). Plants accumulate protective pigments, such as anthocyanins, in the epidermal cells, thereby reducing the damaging effects of solar radiation to the inner cell. Thus, the level of $F 3 H$ in plants affects the ability of plants to resist ultraviolet radiation, because the $F 3 H$ gene is the central locus of the flavonoid synthesis pathway, while the specific relationship remains unknown (Braun and Tevini, 1993; Xu et al., 2008). In this study, the $F 3 H$ families of $C$. nobile were analyzed, and the expression patterns of $F 3 H s$ in various tissues of $C$. nobile were explored. 


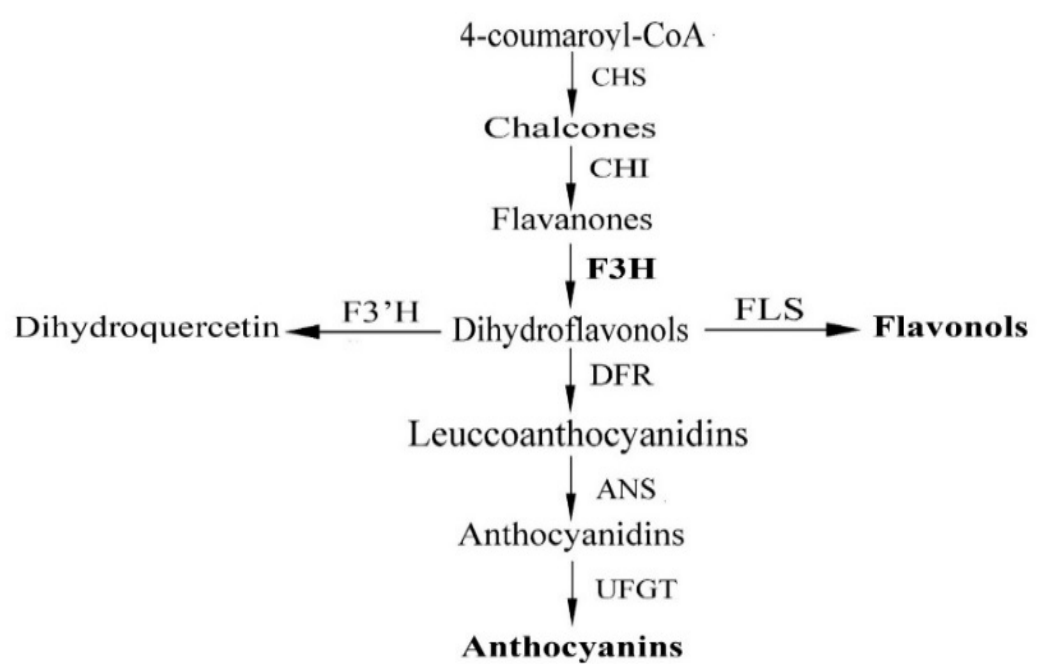

Figure 1. Anthocyanin biosynthetic pathway in plant. Genes encoding enzymes abbreviations are as follows: CHS, chalconesynthase; CHI, chalcone isomerase; F3H, flavanone3-hydroxylase; FLS, flavonol synthase; F3'H, flavonoid 3'-hydroxylase; DFR, dihydroflavonol 4-reductase; ANS, anthocyanidinsynthase; UFGT, UDP-glucose-flavonoid3-Oglycosyltransferase

\section{Materials and Methods}

\section{Plant material}

The seedlings of $C$. nobile were grown in the greenhouse of Yangtze University, Jingzhou, China. The roots, stems, leaves, and flowers of $C$. nobile were collected in April 15th, 2017. All samples were immediately frozen in liquid nitrogen and then kept in the refrigerator at $-80^{\circ} \mathrm{C}$.

\section{$R N A$-Seq data analysis}

In previous studies, transcriptome sequencing of $C$. nobile was performed. The resultant unigenes were further aligned by BlastX to the protein databases. Sequence similarity protein sequences were obtained from the nr database to retrieve sequences sharing the highest sequence similarity with $F 3 H$ genes.

\section{Bioinformatics analysis}

The physicochemical parameters of the four obtained candidate unigenes, which had been described in detail in previous studies, were evaluated using various bioinformatics tools. Vector NTI 11.5.1 was used to determine an open reading frame (ORF). The nucleotide sequences and deduced amino acid sequences were compared through database search by the bioinformatics software on websites (http: //www. ncbi. nlm. nih.gov/BLAST/) and (http://web.expasy.org). Amino acid composition and hydrophobicity analysis were conducted using Bioedit 7.0. Multiple sequence alignments were performed using DNAMAN 6.0, and the conserved protein domains were predicted using InterPro Scan (http:// www.ebi.ac.uk/interpro/). Protein secondary structure prediction was implemented via online tools (https://npsa-prabi.ibcp.fr/cgibin/secpred_sopma.pl). The comparative modeling of the 3D structure of CnF3Hs was generated using the SWISS-MODEL. 3D structural analyses were performed using Weblab Viewerlite. Phylogenetic tree was constructed through the NJ method by using Clustal X 2.0 and MEGA 5.0. The sequences of the transcription group of $C$. nobile were obtained from the pre-transcriptase sequences, and the expression of the $\mathrm{CnF} 3 \mathrm{H}$ gene was determined by FPKM (Mortazavi et al., 2008). 


\section{Results}

\section{Transcriptome-guided unigenes retrieval}

In previous studies, transcriptome sequencing of $C$. nobile was performed (data have been published). The resultant unigenes were further aligned to the protein databases by using BlastX. Sequence similarity protein sequences were obtained from the $\mathrm{nr}$ database to retrieve sequences sharing the highest sequence similarity with F3Hs. Results revealed eleven unigenes showing similarity with $F 3 H$ from RNA-Seq data. Their transcript IDs were listed in Table 1 . These unigenes were further analyzed by NCBI to identify their ORFs. All these unigenes were predicted to contain the length of cDNA sequences (Table 1). After obtaining the sequences by comparison, four highly similar sequences were selected for further analysis (Number: 1, 2, 6, and 7).

Table 1. Unigenes predicted $F 3 H$ genes in the $C$. nobile transcriptome

\begin{tabular}{|c|c|c|c|}
\hline Number & The ID of sequence & $\begin{array}{c}\text { Coding } \\
\text { sequence /bp }\end{array}$ & $\begin{array}{c}\text { Biological function annotation of } \\
\text { Unigene prediction (plant) }\end{array}$ \\
\hline 1 & Group1_Unigene_BMK.3040 & 1373 & Sesamum indicum \\
\hline 2 & Group1_Unigene_BMK.133668 & 1599 & Vitis vinifera \\
\hline 3 & Group1_Unigene_BMK.430 & 759 & Medicago truncatula \\
\hline 4 & Group1_Unigene_BMK.137455 & 1399 & Gossypium arboreum \\
\hline 5 & Group1_Unigene_BMK.134116 & 1930 & Solanum tuberosum \\
\hline 6 & Group1_Unigene_BMK.129252 & 1449 & Nicotiana tabacum \\
\hline 7 & Group1_Unigene_BMK.139451 & 1375 & Saussurea medusa \\
\hline 8 & Group1_Unigene_BMK.2135 & 985 & Prunuspersica \\
\hline 9 & Group1_Unigene_BMK.5151 & 2428 & Coffea canephora \\
\hline 10 & Group1_Unigene_BMK.135344 & 1500 & Sesamum indicum \\
\hline 11 & Group1_Unigene_BMK.135893 & 1375 & Beta vulgaris \\
\hline
\end{tabular}

\section{Identification and characterization of $F 3 H$ proteins of $C$. nobile}

ExPASy online prediction tools were used to predict the protein encoded by the $\mathrm{CnF} 3 \mathrm{H}$ genes, and the predicted amino acid lengths of the four $\mathrm{CnF} 3 \mathrm{H}$ genes (CnF3H1 4) were 300, 350, 341, and 239 bp. The amino acid composition of the $\mathrm{CnF} 3 \mathrm{H}$ s was analyzed using the Bioedit 7.0 software (Figure 2) in which leucine (Leu) had the highest in $\mathrm{CnF} 3 \mathrm{H} 1 \sim 3$ with values of 1,083\%, 9.48\%, and $11.27 \%$. Glutamic (Glu) was the highest in $\mathrm{CnF} 3 \mathrm{H} 4$, which reached $8.44 \%$, whereas cysteine (Cys) was the lowest in $\mathrm{CnF} 3 \mathrm{H} 1$ with only $0.78 \%$, and tryptophan ( $\operatorname{Trp}$ ) was the lowest in $\mathrm{CnF} 3 \mathrm{H} 2 \sim 4$ with values of $1.2 \%, 0.52 \%$, and $1.19 \%$. The contents of the basic amino acids of $\mathrm{CnF} 3 \mathrm{H} 1 \sim 4$ were $4.66 \%, 5.9 \%, 2.7 \%$, and 3.8\% for arginine (Arg), 3\%, 2.6\%, 2\%, and 3.85 for histidine (His), and 7\%, 5.5, 9.9, and 6.3 for lysine (Lys). The contents of acidic amino acids containing aspartic acid (Asp) were 5.2\%, 7.7\%, 5.8\%, and 5\%, respectively, while those containing glutamic acid (Glu) were $5.6 \%, 4.8 \%, 6.88 \%$, and 8.4\%, respectively. As shown in Figure 3, the hydrophilic region was larger than the hydrophobic region (positive region, hydrophobic region; negative, hydrophilic), further indicating that the protein encoded by the $\mathrm{CnF} 3 \mathrm{Hs}$ is a hydrophilic protein. In addition, both the $\mathrm{N}$ - and C-termini of the $\mathrm{CnF} 3 \mathrm{H}$ protein were hydrophilic and showed strong hydrophilicity or hydrophobicity in some regions.

The F3H protein sequences of other plants were searched on the NCBI website (Table 2), and the $\mathrm{CnF} 3 \mathrm{H}$ protein sequences were compared with those of the other plants F3H by using DNAMAN 6.0. The results shown in Figure 4 indicated that the protein sequences of $\mathrm{CnF} 3 \mathrm{H} 1 \sim 4$ were homologous with those of other plant $\mathrm{F} 3 \mathrm{H}$ proteins with similarity of $62.70 \%$. Conserved domains of $\mathrm{CnF} 3 \mathrm{H}$ protein were predicted using an online analysis tool InterPro. Results displayed that four $\mathrm{CnF} 3 \mathrm{H}$ s belonged to the isopenicillin $\mathrm{N}$ synthase-like superfamily, which all had two conserved domains, non-haem dioxygenase N-terminal domain (IPR027443), and oxoglutarate/iron-dependent dioxygenase (IPR005123) (Figure 4). According to Shen et al. (2006) and Huang et al. (2013), the analysis revealed that the four $\mathrm{CnF} 3 \mathrm{H}$ proteins contained some differences in binding 
106

sites, which conserved His and Asp bound to $\mathrm{Fe}^{2+}$, and Arg and Ser were involved in the combination of 2-Oketoglutarate (Figure 4). Differences were observed in polypeptide dioxygenases with specific residues in the two highly conserved regions, and the binding sites for amino acid ferrous iron and $\alpha$-ketoglutarate were the same in the four $\mathrm{CnF} 3 \mathrm{H}$.

To better understand the $\mathrm{CnF} 3 \mathrm{H}$ protein, we predicted the secondary structure by using online tools (https://npsa-prabi.ibcp.fr/cgi-bin/secpred_sopma.pl). As shown in Figure 5A, CnF3H1 4 peptides were composed of $\alpha$-helices represented in blue, random coils represented in purple, $\beta$-turns represented in green, and extension chains represented in red. Moreover, the composition and proportion of the four $\mathrm{CnF} 3 \mathrm{H}$ secondary structures were basically the same. $\alpha$-Helixes and random coils were the most abundant structural elements in the $\mathrm{CnF} 3 \mathrm{H}$ secondary structure, while extension chains and $\beta$-folds were intermittently distributed in the protein (Figure 5B). A comparative modeling of the $3 \mathrm{D}$ structure of $\mathrm{CnF} 3 \mathrm{H}$ s were performed using SWISS-MODEL based on the highest query coverage of the template Papaver somniferum (5o7y.1) (Kluza et al., 2018). 3D structural analyses were performed using Weblab Viewerlite to further elucidate the CnF3H protein. As seen from Figure 6, the four $\mathrm{CnF} 3 \mathrm{H}$ proteins were approximately spherical, similar to the other F3Hs. The 2-ODD enzyme structure was located at the core position of the entire structure formed by the jellyroll motif, and the active sites of conjugated His and Asp residues of $\mathrm{Fe}^{2+}$ and Fe were buried in the center of the enzyme. The surface of the four proteins had a conservative $\alpha$-helix, which had a leucine zipper structure composed of Lue, Ile, Val, and Met, while Leu faced the center of the molecule and could not interact with the other proteins outside (Shen et al., 2006).

\section{Phylogenetic analysis of $\mathrm{FH} H$ proteins from different plant species}

To better understand the molecular evolution relationship of F3Hs protein, we used the Clustal X 2.0 and MEGA 5.0 software to compare the deduced amino acid sequence of $\mathrm{CnF} 3 \mathrm{H} 1 \sim 4$ with the $\mathrm{F} 3 \mathrm{H}$ of other plants on BLAST to construct the phylogenetic tree with the neighbor-joining method (Table 2). The results in Figure 7 indicated that the phylogenetic tree of $\mathrm{F} 3 \mathrm{H}$ was divided into five branches, including Brassicaceae, Solanaceae, Asteraceae, Rosaceae, and Gramineae.
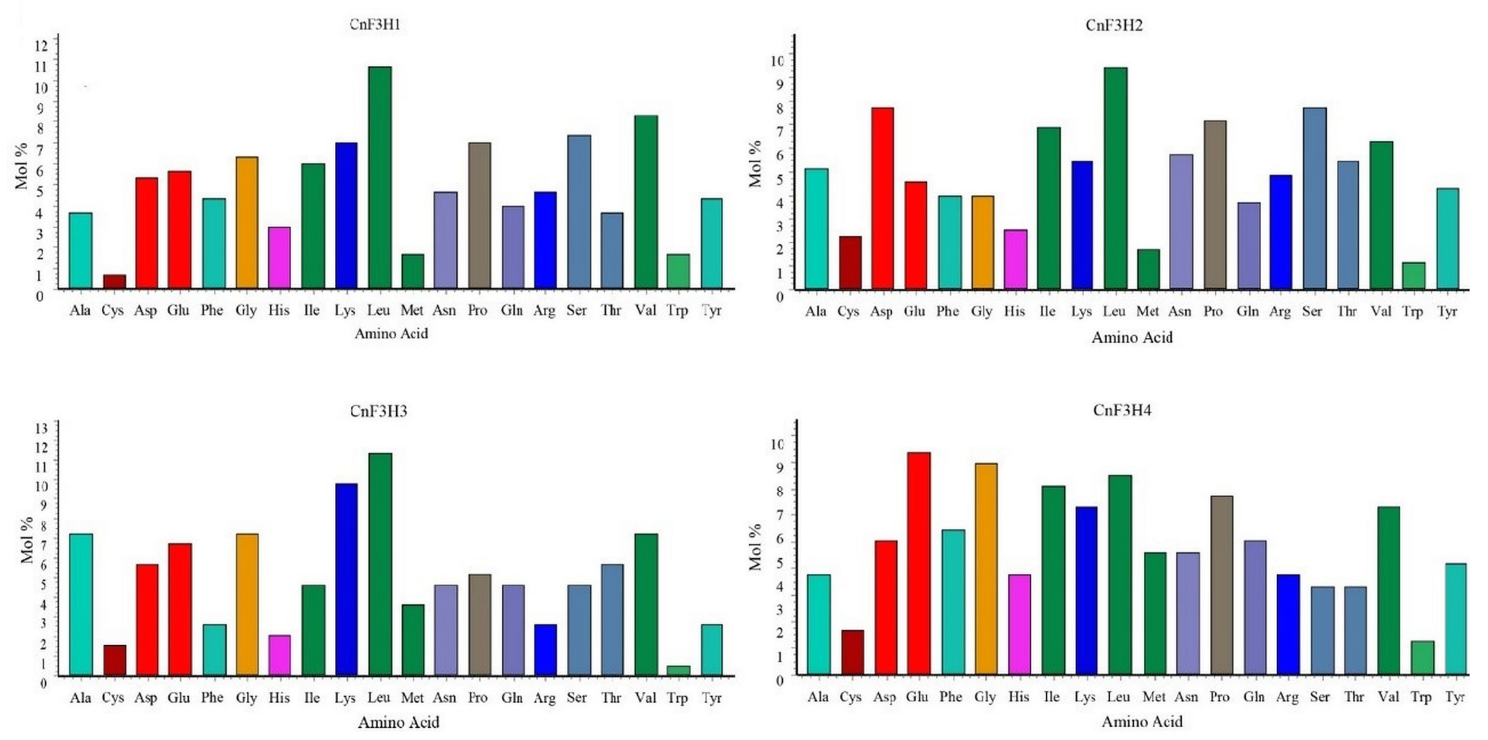

Figure 2. The amino acid composition of the $\mathrm{CnF} 3 \mathrm{Hs}$ 

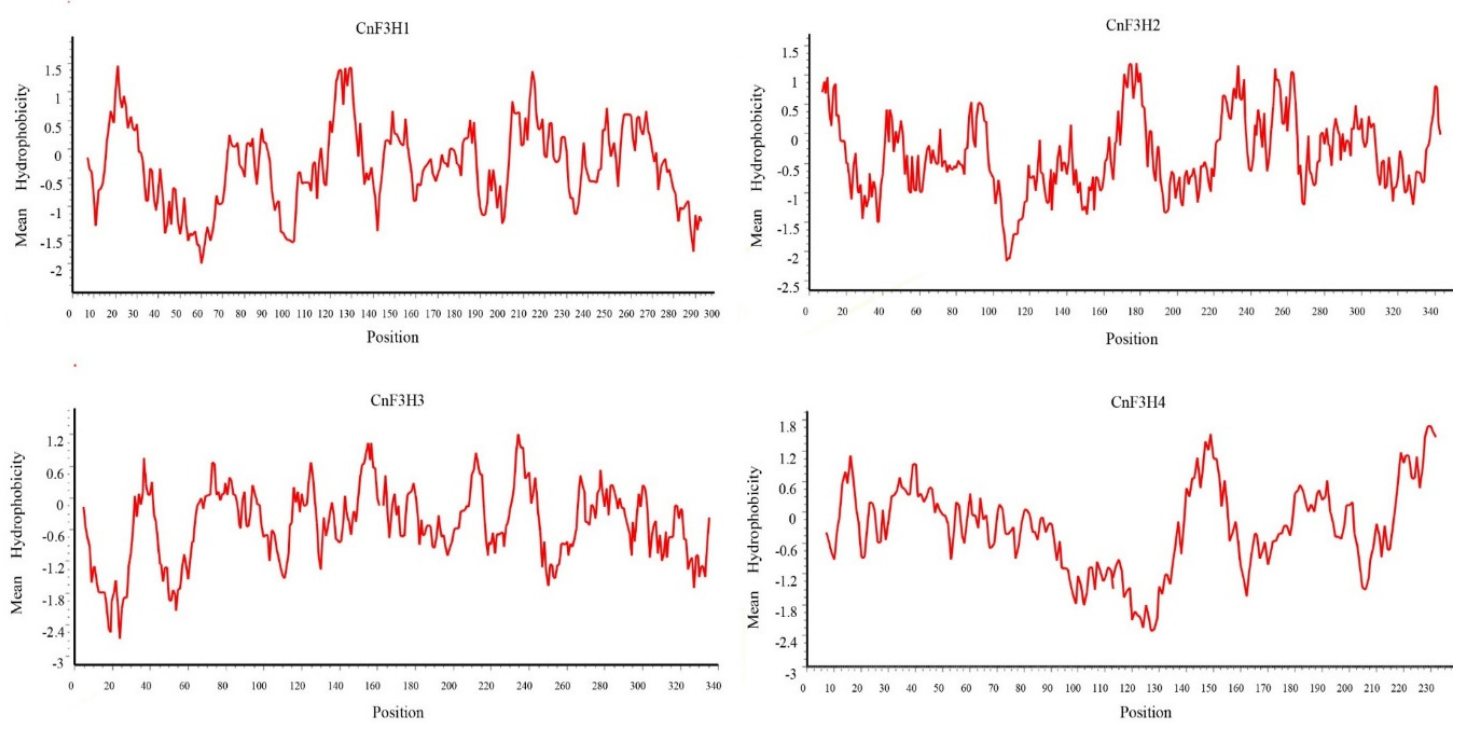

Figure 3. Analysis of $\mathrm{CnF} 3 \mathrm{Hs}$ hydrophobicity. The positive region is the hydrophobic region and the negative is hydrophilic

The evolution of $\mathrm{CnF} 3 \mathrm{Hs}$ basically accorded with the characteristics of plant taxonomy and had obvious species characteristics. Plants of the same family were on the same branch of the evolutionary tree. Brassica rapa, Brassica oleracea, Raphanus sativus, and Camelina sativa belonged to Brassicaceae. Solanum tuberosum and Solanum pennellii were classified under Solanaceae. Brachypodium distachyon, Oryza brachyantha, and Oryza sativa belonged to Gramineae. Prunus mume, Prunus avium, and Prunus persica were clustered under Rosaceae. The phylogenetic tree displayed that $\mathrm{CnF} 3 \mathrm{H} 2, \mathrm{CnF} 3 \mathrm{H} 3$, and $\mathrm{CnF} 3 \mathrm{H} 4$ were clustered with Chrysanthemum morifolium and Dablia pinnata, which belonged to Asteraceae. The genetic relationship between $\mathrm{CnF} 3 \mathrm{H} 2$ and $\mathrm{CnF} 3 \mathrm{H} 4$ was the nearest, that between $\mathrm{CnF} 3 \mathrm{H} 3$ and Chrysanthemum morifolium was closest, and that between $\mathrm{CnF} 3 \mathrm{H} 1$ and Solanaceae was the closest. Some changes possibly occurred due to some functional changes in the process of evolution. In terms of species, Asteraceae plants appeared earlier than the other plants. The genetic relationship between the $\mathrm{CnF} 3 \mathrm{H} 2 \sim 4$ and $\mathrm{CnF} 3 \mathrm{H} 1$ was different, but the sequence alignment of the amino acids showed that $\mathrm{CnF} 3 \mathrm{H}$ had the same conservative region. Our results indicated that $\mathrm{CnF} 3 \mathrm{Hs}$ were based on sequence characteristics and conserved structures (conserved motifs) that shared common evolutionary ancestors with the $\mathrm{F} 3 \mathrm{H}$ from other plants.

\section{Expression patterns of $\mathrm{CnF} 3 \mathrm{H}$ s in different tissues of C. nobile}

As shown in Figure 8, the RPKM values in the roots, stems, leaves, and flowers were 3.323948, 2.796359, 1.86812, and 20.99907 for CnF3H1, 0.453682846, 0.83263989, 0.83263989, and 3.949693814 for CnF3H2, $16.17092858,15.23330874,2.854766389$, and 291.2184552 for $C n F 3 H 3$, and 18.78227185, 10.49824245, 6.061711013, and 4.742910978 for CnF3H4, respectively. Hence, CnF3H1 4 had considerably difference in the expression of different tissues. $\mathrm{CnF} 3 \mathrm{H} 1 \sim 3$ had highest expression level in the flowers, and $\mathrm{CnF} 3 \mathrm{H} 4 \mathrm{~h}$ had the highest expression level in the roots. However, the lowest expression of the four $\mathrm{CnF} 3 \mathrm{H}$ s in different tissues of $C$. nobile were not the same; the expression level of $\mathrm{CnF} 3 \mathrm{H} 1$ was the lowest in the leaves, $\mathrm{CnF} 3 \mathrm{H} 2$ expression level was lowest in the roots, $\mathrm{CnF} 3 \mathrm{H} 3$ expression was lowest in the leaves, and the expression quantity of $\mathrm{CnF} 3 \mathrm{H} 4$ was lowest in the flowers. 


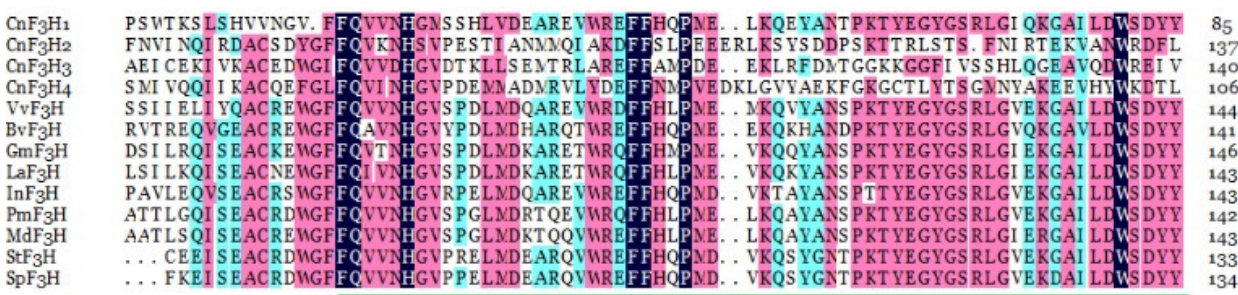

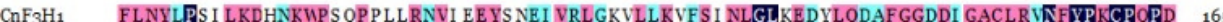
$\mathrm{CnF}_{3} \mathrm{H}_{2}$ RLHCYP. LEDYVHEWPT NPT NFRAHVKEYCT VRGLALELI EAI SES LGLDKDYI AKQLG. . KHGQHAALNYP PCPOPD 165

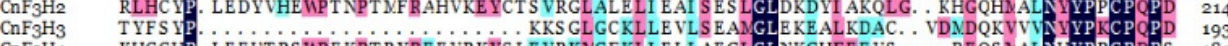
$\mathrm{CnF}_{3} \mathrm{H}_{4}$ KHGCHP. LEEHT PS WP E KPT RYREE VRKYS I E VRKNGF KI LELI AE GLGL NKGHFEE VS. . . R REQS NAI NFYPPCPDPS 181

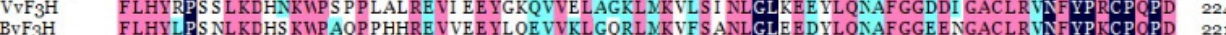

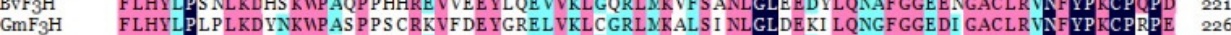

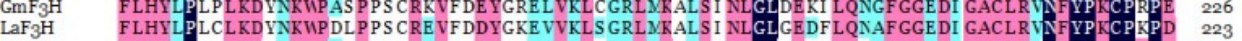

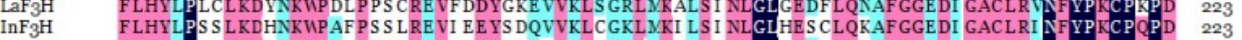

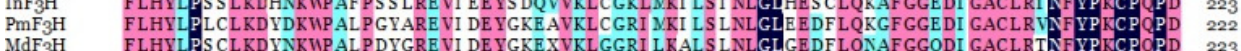

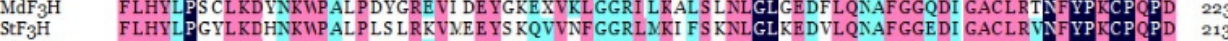

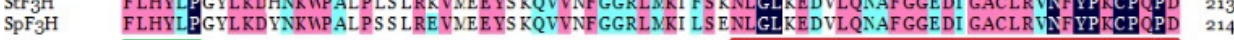

作

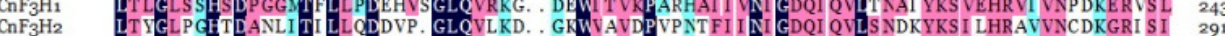
$\mathrm{CnF}_{3} \mathrm{H}_{3}$ $\mathrm{CnF}_{3} \mathrm{H}_{4}$ $\mathrm{VvF}_{3} \mathrm{H}$ $\mathrm{BvF}_{3} \mathrm{H}$

$\mathrm{GmF}_{3} \mathrm{H}$

$\mathrm{LaF}_{3} \mathrm{H}$

$\mathrm{InF}_{3} \mathrm{H}$

MaFsh

$\mathrm{StF}_{3} \mathrm{H}$

$\mathrm{SpF}_{3}$

$\mathrm{CnF}_{3} \mathrm{H}_{1}$

$\mathrm{CnF}_{3} \mathrm{H}_{2}$

$\mathrm{CnF}_{3} \mathrm{H}_{3}$

$\mathrm{CnF}_{3} \mathrm{H}_{4}$

$\mathrm{VvF}_{3} \mathrm{H}$

$\mathrm{BvF}_{3} \mathrm{H}$

$\mathrm{GaF}_{3} \mathrm{H}$

$\mathrm{InF}_{3} \mathrm{H}$

$\mathrm{PmF}_{3} \mathrm{H}$

$\mathrm{StF}_{3} \mathrm{H}$

$\mathrm{SpF}_{3} \mathrm{H}$

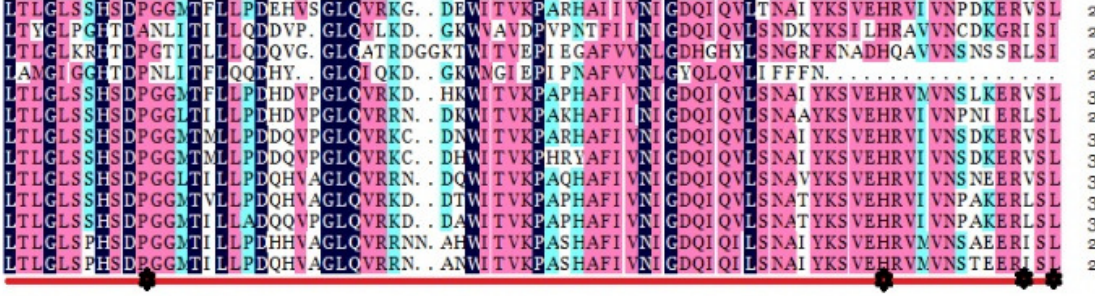

AYFFNPKSDI LI KPATELVT. . . . . S SNVP. ALYPPATFDE YRLFI RT KGPQGKSQV. ESLK. SPR. . . TFYCPS RDAVI S PAPEL VN. ....... DDQP. AI YRS FT YGE YCDKFVT RGLATENCLDLF NAS KST. ATEPAPNAI VYPLKVNE GETS I NEEPI TF NE MYKKKVS T DLELARL KKLAKAKQQDLE KVKPI KS I FA.

AFFYNPKS DI LI EPVRALVT. . . . . P PTTP. ALYPGNTFDQYRLYI RNRGPRGKSQV. ESLK. SPR. . . AFFFNPRGELLI EPAKKL VT. . ...... PENP. AL YP P NT FNE YRL YI RL KGPQGKSQV. ESLK. SPR. . AF FYNPKS DI PI EPI KELVT. . . . . PE PE. S L YPANT FDE YRLFI RNRGPRGKS QV. ESLK. SPR. . AFF YNPKS DI PI EPAKE L VT. ........ LDKP. AL YP ANT FDQYRL FI RNRGPRGKS QV. ES LK. SRT. . AYFYNPRGELL LQPNKELI T. . . . . . PENP. PL YPANTFNE YRLYI RT KGPRGKS QI GQSTK. SPR. . AFFYNPKSDI AI EPAKELVT. ........ PERP. ALYT PNT FNE YRL YI RLNGPRGKSQV. DS LK. SPRK. . AFF AFFYNP KSDLMI EPVKELLT. ........ THNI S PLYPPRTFDQYRLYI RT KGPQGKSQLGES NKS NPQHDKC 301 301 292 . \\ 291 302 299 304 301}

Figure 4. Multiple alignment of $\mathrm{CnF} 3 \mathrm{H}$ s with the $\mathrm{F} \# \mathrm{H}$ from other plants. Oxoglutarate/iron-dependent dioxygenase conserved domain was underlined of red line and non-haem dioxygenase $\mathrm{N}$-terminal domain were underlined of green line. Asterisks indicated the conserved amino acid residues used to attach ferrous ions and participating in 2-oxoglutarate binding. The identical amino acids were showed in white foreground and navy-blue background; the conservative amino acid sequence was indicated in black foreground and red background; the non-similar amino acids were indicated with black foreground and white background. The species, protein abbreviation and GenBank accession numbers were as following: $\mathrm{CnF} 3 \mathrm{H}$ : Chamaemelum nobile VvF3H: Vitis vinifera, XP_002272995.1; BvF3H: Beta vulgaris, XP_010689599.1; GmF3H: Glycine max, XP_003552326.1; LaF3H: Lupinus angustifolius, XP_019449875.1; InF3H: Ipomoea nil, XP_019150827.1; PmF3H: Prunus mume, XP_008233765.1; MdF3H: Malus domestica, XP_008343625.1; StF3H: Solanum tuberosum, XP_006356460.1; SpF3H: Solanum pennellii, XP_015068457.1 
A

CnF3H1

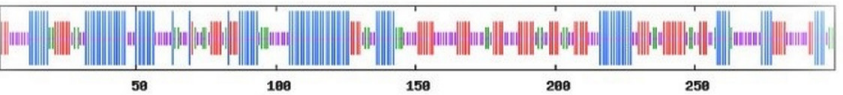

$\mathrm{CnF3H2}$

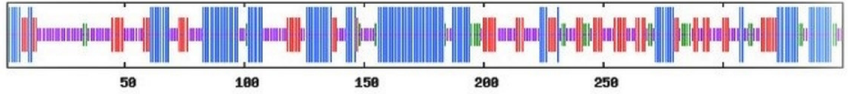

CnF3H3

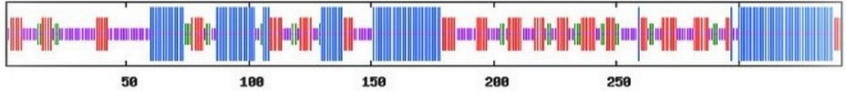

$\mathrm{CnF3H4}$

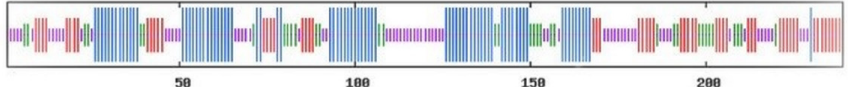

B

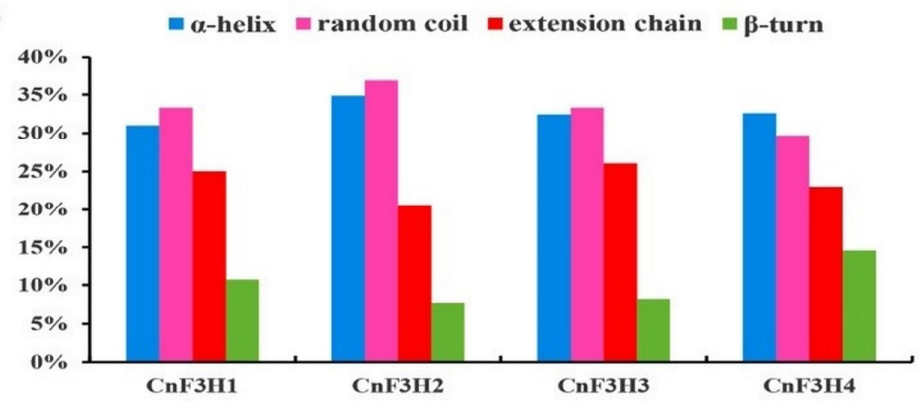

Figure 5. Secondary structure of the $\mathrm{CnF} 3 \mathrm{H}$ s protein. A represented the structure of $\mathrm{CnF} 3 \mathrm{H} 1, \mathrm{CnF} 3 \mathrm{H} 2$, $\mathrm{CnF} 3 \mathrm{H} 3$ and $\mathrm{CnF} 3 \mathrm{H} 4$ proteins; $\mathrm{B}$ represented the percentage of a-helix, extended chain, $\beta$-fold and random coil. A-helixes were represented by blue, random coils were represented by purple, $\beta$-turns were represented by green and extension chains were represented by red

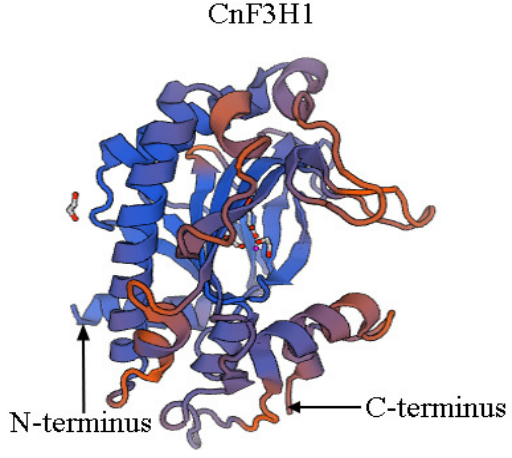

$\mathrm{CnF} 3 \mathrm{H} 3$

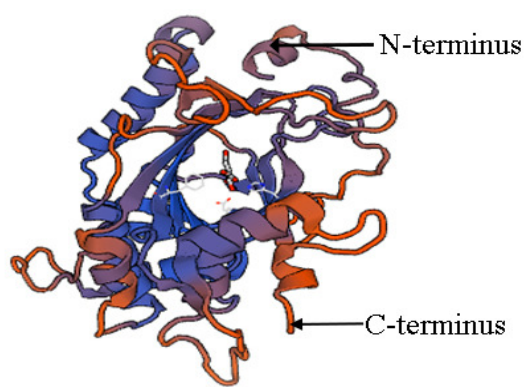

$\mathrm{CnF} 3 \mathrm{H} 2$

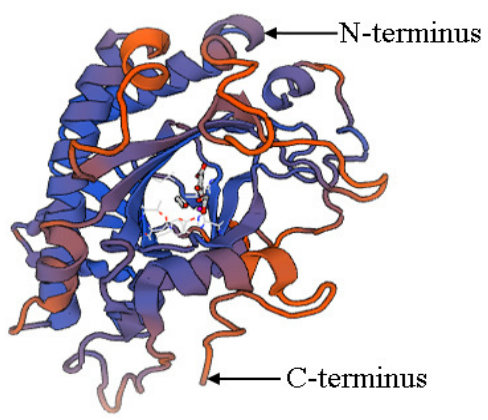

$\mathrm{CnF} 3 \mathrm{H} 4$

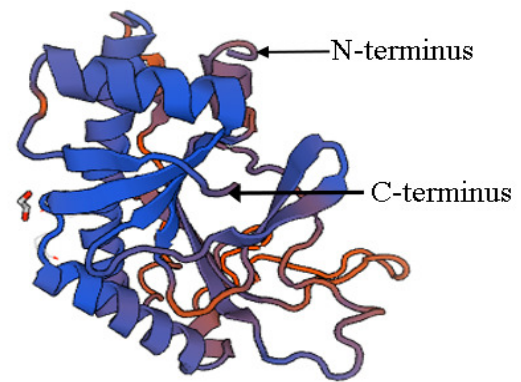

Figure 6. The three-dimensional model of $\mathrm{CnF} 3 \mathrm{Hs}$. The a-helices were indicated by helices. The sheets were indicated by patches. Turns and loops are indicated by lines 


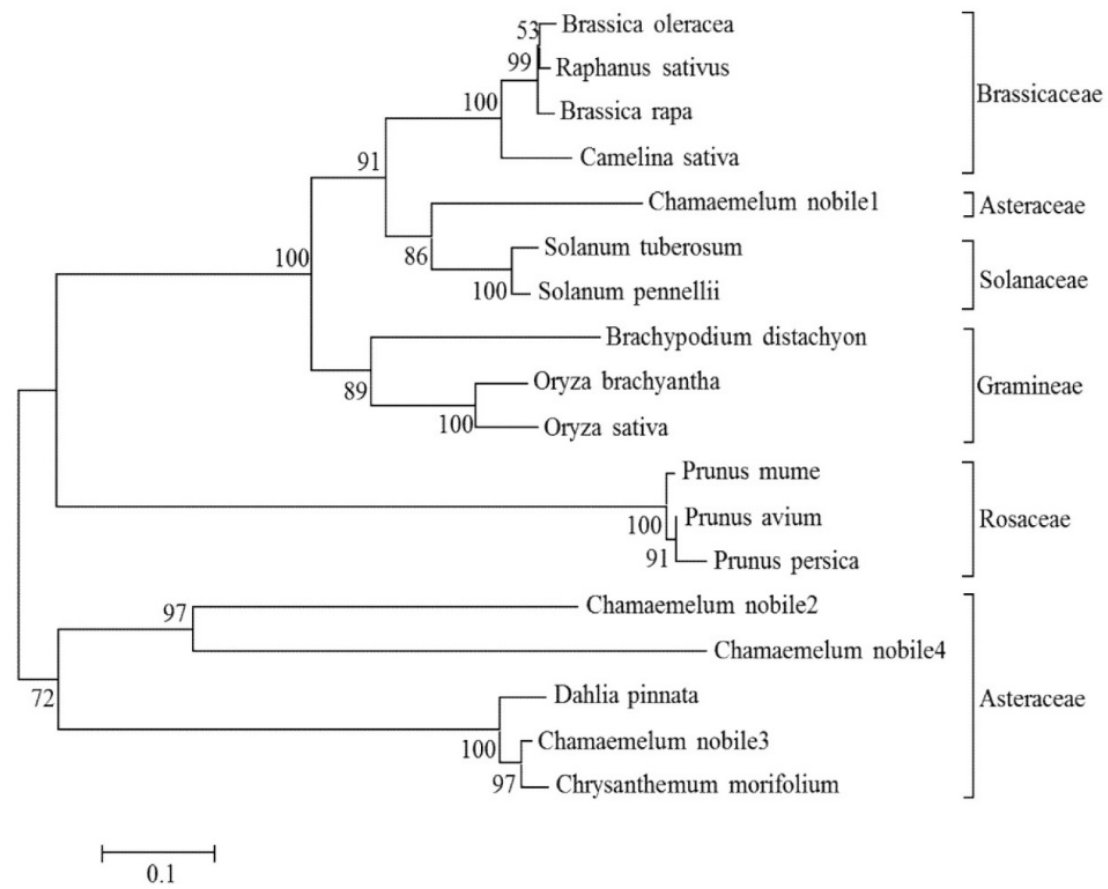

Figure 7. Phylogenic tree of $\mathrm{F} 3 \mathrm{Hs}$ amino acid sequences from various species. The tree was constructed by the MEGA 5.0 software with the neighbor-joining method and 1000 bootstrap replicates. The species, protein abbreviation and GenBank accession numbers were as following: BrF3H: Brassica rapa, XP_009130890.1; BoF3H: Brassica oleracea, XP_013623255.1; RsF3H: Raphanus sativus, XP_018473361.1; CsF3H: Camelina sativa, XP_010491092.1; StF3H: Solanum tuberosum, XP_006356460.1; SpF3H: Solanum pennellii, XP_015068457.1; CmF3H: Chrysanthemum morifolium, AAB97310.1; DpF3H: Dablia pinnata, BAJ21534.1; PmF3H: Prunus mume, XP_008233895.1; PaF3H: Prunus avium, XP_021810338.1; PpF3H: Prunus persica, XP_007222581.1; BdF3H: Brachypodium distachyon, XP_003567249.1; ObF3H: Oryza brachyantha, XP_006654951.1; OsF3H: Oryza sativa, XP_015624858.1
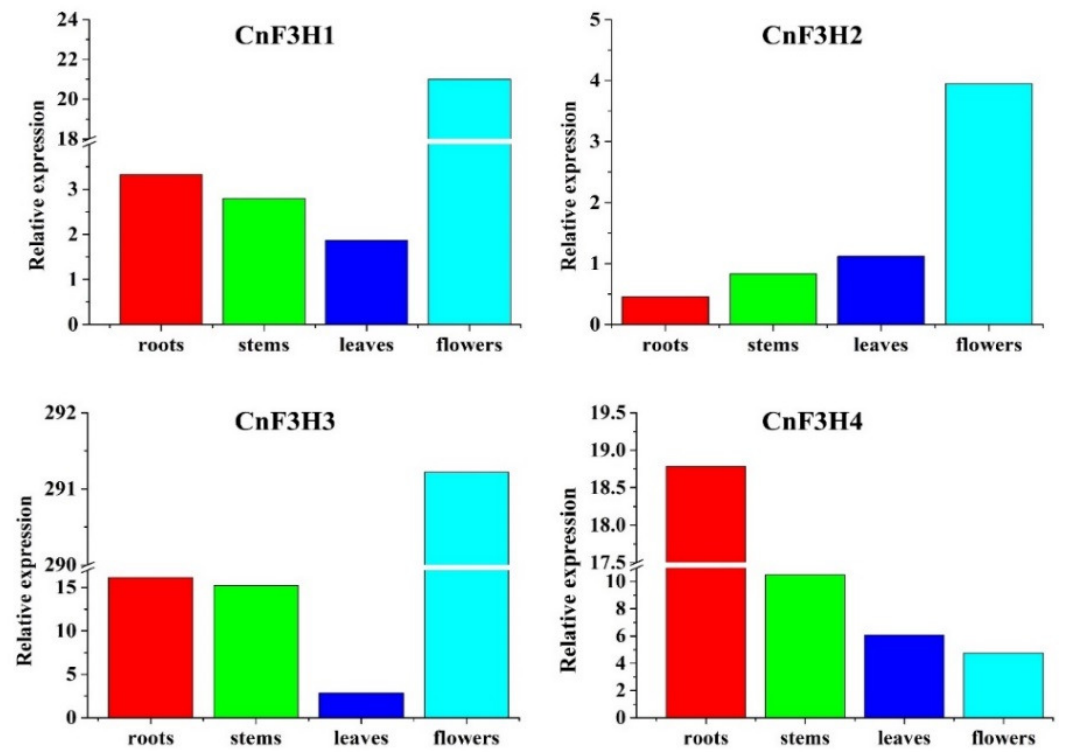

Figure 8. Expression patterns of $\mathrm{CnF} 3 \mathrm{Hs}$ in different tissues of C. nobile 


\section{Discussion}

A majority of $F 3 H$ genes were involved in the regulation of flavonoid biosynthesis based on the cloned F3H genes from many plants (Huang et al., 2013; Ma and Guo, 2014; Zhou et al., 2015) but those in C. nobile were rarely reported. In this study, the $F 3 H$ families were determined from $C$. nobile transcriptome data. Four highly similar sequences were selected for further analysis. $\mathrm{CnF} 3 \mathrm{H} 1 \sim 4$ contained two conserved isopenicillin $\mathrm{N}$ synthase-like and oxoglutarate/iron-dependent dioxygenase domains, which were typical protein structures of $\mathrm{F} 3 \mathrm{H}$ families and were involved in flavonoid biosynthesis. Four $\mathrm{CnF} 3 \mathrm{H}$ proteins contained some differences in binding sites (Figure 4) because of the differences in polypeptide dioxygenases with specific residues in two highly conserved regions. Furthermore, $\mathrm{CnF} 3 \mathrm{H}$ encoded protein belonging to the $\mathrm{F} 3 \mathrm{H}$ gene family in the 2OG-FeII_Oxy dioxygenase family. The conservation of these motifs plays key roles in flavonoid biosynthesis (Huang et al., 2013). Thus, CnF3Hs may have the same function as the $\mathrm{F} 3 \mathrm{H}$ in other plants in flavonoid biosynthesis. Our results were similar to previous studies about F3Hs in tea (Hu et al., 2010), Saussurea medusa (Jin et al., 2005), and Ginkgo biloba (Shen et al., 2006) plants. The amino acid compositions of the four $\mathrm{CnF} 3 \mathrm{H}$ s were similar (Figure 2). Simultaneously, the amino acid composition of four F3H proteins the important domains were highly homologous, presumably because some plants need to accumulate many flavonoids, and the production of flavonoids and anthocyanin are mainly determined by the flow of metabolic pathways through the formation of the intermediate metabolite, and these highly homologous regions may play some certain functions in these processes. Therefore, $\mathrm{F} 3 \mathrm{H}$ must maintain a very conservative genetic stability and evolutionary homogeneity. The composition and proportion of the four $\mathrm{CnF} 3 \mathrm{H}$ secondary structures were the basically same, and the 3-D structures were consistent with the secondary structures (Figure 5 and 6). Similar to the other $\mathrm{F} 3 \mathrm{Hs}$, the binding sites of $\mathrm{CnF} 3 \mathrm{H}$ proteins mainly participated in and regulated protein metabolism, post-translational modification, and processing, which were important for protein activity (Peng, 2010; Zhang et al., 2010). As shown in Figure 7, a significant genetic relationship between $\mathrm{CnF} 3 \mathrm{Hs}$ and the other plants, and the phylogenetic tree displayed that $\mathrm{CnF} 3 \mathrm{H} 2, \mathrm{CnF} 3 \mathrm{H} 3$, and $\mathrm{CnF} 3 \mathrm{H} 4$ were clustered in Asteraceae. The genetic relationship between $\mathrm{CnF} 3 \mathrm{H} 1$ and Solanaceae was the closest, because some changes in the gene lead to changes in certain functions during evolution, which need to be further confirmed by biotechnologies in the future. Although the genetic relationship between the $\mathrm{CnF} 3 \mathrm{Hs}$ was different, the sequence alignment of the amino acids showed that the $\mathrm{CnF} 3 \mathrm{H}$ s had the same conservative region. Thus, $\mathrm{CnF} 3 \mathrm{H}$ s were based on sequence characteristics and conserved structures (conserved motifs) that shared common evolutionary ancestors with the $\mathrm{F} 3 \mathrm{H}$ from other plants. Our findings will provide a theoretical basis for elucidating the functions of $\mathrm{F} 3 \mathrm{H}$ in $C$. nobile, and the analysis results are of great significance to explore the mechanism of flavonoid synthesis at the molecular level.

In addition, some of the main components of flavonoids such as celery, rutin, luteolin, and quercetin, have been determined in other plants (Stobiecki and Kachlicki, 2006). However, the contents of flavonoids in various tissues of $C$. nobile remain unclear. The expression of $F 3 H$ gene can affect flavonoid metabolites, and it also plays a key role in the synthesis of flavonoids (Kim et al., 2008). In general, the expression of $F 3 H$ in flowers was relatively high in plants with flowers as the main application value (Zhou et al., 2015). In this paper, the FPKM values indicated that $C n F 3 H 1 \sim 4$ had a remarkable difference in the expression of different tissues of C. nobile, the $\mathrm{CnF} 3 \mathrm{HI} \sim 3$ had highest expression level in the flowers, and the expression level of $\mathrm{CnF} 3 \mathrm{H} 4$ was highest in the roots (Figure 8). The same result was obtained in Camellia nitidissima, the expression level of $\mathrm{F3H}$ gene was the highest in the flowers, which had a difference expression in various organs (Zhou et al., 2015). Lycoris radiata had the same result (Huang et al., 2013). The above results demonstrated that the expression levels of F3H in different plant tissues were different, which may be the differences in organs that accumulation of flavonoid and $\mathrm{F} 3 \mathrm{H}$ gene was likely to provide several flavonoids in the flowers. As reported in tea, the expression level of $F 3 H$ gene is the highest in the mature leaves, and the expression level of $F 3 H$ gene expression 
112

is regulated by light ( $\mathrm{Hu}$ et al., 2014). The $F 3 H$ gene may be related to the accumulation of flavonoids in tea leaves. Generally, the expression of $F 3 H$ gene may be differing in different plant tissues, and the amount of expression is higher in tissues with wide application value. This research will lay theoretical foundation for improving the yield of flavonoids in $C$. nobile. At present, the research about $F 3 H$ gene is not deep enough, and its function and the relationship between related genes in the flavonoid biosynthesis pathway remain unclear. $\mathrm{F} 3 \mathrm{H}$ gene plays a key role in the flavonoid biosynthesis pathway. To understand the biosynthesis of flavonoids and other active substances in $C$. nobile, we will determine the correctness of the screening sequence through gene cloning and further to confirm the expression patterns of these genes by real-time PCR. We will also further to verify the function of the $F 3 H$ gene in $C$. nobile by transgenic technology. Our results will further reveal the regulation of the $F 3 H$ gene on flavonoid biosynthesis and the correlation between the related genes in the synthetic pathway and clarify the mechanism of action of the $F 3 H$ gene in the formation of flavonoids.

\section{Conclusions}

In this study, we screened four $\mathrm{CnF} 3 \mathrm{H}$ genes and successfully characterized them. Bioinformatics analysis showed that $\mathrm{CnF} 3 \mathrm{H} 1 \sim 4$ had a typical protein structure of $\mathrm{F} 3 \mathrm{H}$ families, and $\mathrm{CnF} 3 \mathrm{Hs}$ had the same conservative region of the amino acids. The expression patterns of $\mathrm{CnF} 3 \mathrm{Hs}$ in the roots, stems, leaves, and flowers indicated substantial difference in the expression of different tissues according the RPKM values. This study will lay a theoretical foundation to further understand the specific function of $F 3 H$ families in the flavonoid metabolism pathway.

\section{Acknowledgements}

This work was supported by National Natural Science Foundation of China (No. 31400603).

\section{Conflict of Interests}

The authors declare that there are no conflicts of interest related to this article.

\section{References}

Achterrath-Tuckermann U, Kunde R, Flaskamp E, Isaac O, Thiemer K (1980). Pharmacological investigations with compounds of chamomile. V. Investigations on the spasmolytic effect of compounds of chamomile and Kamillosan on the isolated guinea pig ileum. Planta Medica 39(1):38-50.

Braun J, Tevini M (1993). Regulation of UV-protective pigment synthesis in the epidermal layer of rye seedlings (Secale cereale L. cv. Kustro). Photochemistry and Photobiology 57(2):318-323.

Carnat A, Carnat AP, Fraisse D, Ricoux L, Lamaison JL (2004). The aromatic and polyphenolic composition of Roman camomile tea. Fitoterapia 75(1):32-38.

Charrier B, Coronado C, Kondorosi, A, Ratet P (1995). Molecular characterization and expression of alfalfa (Medicago sativa L.) flavanone-3-hydroxylase and dihydroflavonol-4-reductase encoding genes. Plant Molecular Biology 29(4):773-786. 
Cheng S, Yan J, Meng X, Zhang W, Liao Y, Ye J, Xu F (2018). Characterization and expression patterns of a cinnamate-4hydroxylase gene involved in lignin biosynthesis and in response to various stresses and hormonal treatments in Ginkgo biloba. Acta Physiologiae Plantarum 40(1): 7.

Deboo GB, Albertsen MC, Taylor LP (1995). Flavanone 3-hydroxylase transcripts and flavonol accumulation are temporally coordinate in maize anthers. The Plant Journal 7(5):703-713.

Dooner HK, Robbins TP, Jorgensen RA (1991). Genetic and developmental control of anthocyanin biosynthesis. Annual Review of Genetics 25(1):173-199.

Elomaa P, Honkanen J, Puska R, Seppänen P, Helariutta Y, Mehto M, Teeri TH (1993). Agrobacterium-mediated transfer of antisense chalcone synthase cdna to gerbera hybrida inhibits flower pigmentation. Nature Biotechnology 11(4):508-511.

Fan R, Huang M, Zhong H, Wu J (2014). Cloning and expression of flavanone 3-hydroxylase from Strelitzia reginae Banks. Molecular Plant Breeding 12(1):168-172.

Farhoudi R (2013). Chemical constituents and antioxidant properties of matricaria recutita and Chamaemelum nobile essential oil growing wild in the south west of Iran. Journal of Essential Oil Bearing Plants 16(4):531-537.

Ma G, Guo JP (2014). In silico cloning and sequence analysis of F3H gene in Phaseolus coccineus. Modern Food Science and Technology 30(4):6-9+33.

$\mathrm{Hu}$ XJ, Xu YJ, Gao LP, Xia T, Wang YS (2014). Cloning and functional analysis of flavanone 3-hydroxylase gene $(F 3 H)$ in tea (Camellia sinensis). Journal of Agricultural Biotechnology 22(3):309-316.

Huang CH, Gao YH, Zhu YQ, Tong ZK, Jiang XF (2013). Cloning and expression analysis of flavanone 3-hydroxylase gene $L r F 3 H$ from Lycoris radiata. Acta Horticulturae Sinica 40(5):960-970.

Meer IMVD, Stam ME, Tunen AJV, Mol JN, Stuitje AR (1992). Inhibition of flavonoid biosynthesis in Petunia anthers by antisense RNA: a novel way to engineer nuclear male sterility. Angiosperm Pollen and Ovules, New York pp 22-27.

Irmisch S, Krause ST, Kunert G, Gershenzon J, Degenhardt J, Köllner TG (2012). The organ-specific expression of terpene synthase genes contributes to the terpene hydrocarbon composition of chamomile essential oils. BMC Plant Biology 12(1):84-97.

Jaziri M, Fauconnier ML, Guo YW, Marlier M, VanhaelenM (1999). Genetic Transformation of Anthemis nobilis L. (Roman Chamomile). Transgenic Medicinal Plants, Berlin, Heidelberg pp 47-54.

Jiang F, Wang JY, Jia HF, Jia WS, Wang HQ, Xiao M (2013). RNAi-Mediated silencing of the flavanone 3-hydroxylase gene and its effect on flavonoid biosynthesis in strawberry fruit. Journal of Plant Growth Regulation 32(1):182190.

Jin Z, Grotewold E, Qu W, Fu G, Zhao D (2005). Cloning and characterization of a flavanone 3-hydroxylase gene from Saussurea medusa. DNA Sequence, 16(2):121-129.

Kim BG, Kim JH, Kim J, Lee C, Ahn JH (2008). Accumulation of flavonols in response to ultraviolet-b irradiation in soybean is related to induction of flavanone 3-beta-hydroxylase and flavonol synthase. Molecules and Cells $25(2): 247-252$.

Kluza A, Niedzialkowska E, Kurpiewska K, Wojdyla Z, Quesne M, Kot E, Borowski T (2018). Crystal structure of thebaine 6-O-demethylase from the morphine biosynthesis pathway. Journal of Structural Biology 202(3):229235.

Kumar A, Singh B, Singh K (2015). Functional characterization of flavanone 3-hydroxylase gene from Phyllanthus emblica (L.). Journal of Plant Biochemistry and Biotechnology 24(4):453-460.

Li J, Oulee TM, Raba R, Amundson RG, Last RL (1993). Arabidopsis flavonoid mutants are hypersensitive to UV-B irradiation. Plant Cell 5(2):171-179.

Ma CM, Winsor L, Daneshtalab M (2007). Quantification of spiroether isomers and herniarin of different parts of Matricaria matricarioides and flowers of Chamaemelum nobile. Phytochemical Analysis 18(1):42-49.

Melegari M, Albasini A, Pecorari P, Vampa G, Rinaldi M, Rossi T, Bianchi A (1988). Chemical characteristics and pharmacological properties of the essential oils of Anthemis nobilis. Fitoterapia 59(6):449-455.

Meng Xiangxiang, Yan Jiaping, Liao Yonging, Chang Jie, Xu Feng (2016). Cloning and expression analysis of $H M G R$ gene from Chamaemelum nobile. Acta Agriculturae Boreali Sinica 31(6):68-75. 


\section{4}

Cheng S et al. (2020) Not Bot Horti Agrobo 48(1):102-115.

Meng X, Zhang W, Xu F, Yan J, Liu X, Liao YL, Chang J (2016). Cloning and sequence analysis of mevalonate kinase gene $(C n M V K)$ from Chamaemelum nobile. International Journal of Current Research in Biosciences and Plant Biology 3(11):23-28.

Middleton E, Kandaswami C, Theoharides TC (2000). The effects of plant flavonoids on mammalian cells: implications for inflammation, heart disease, and cancer. Pharmacological Reviews 52(4):673-751.

Mortazavi A, Williams BA, Mccue K, Schaeffer L, Wold B (2008). Mapping and quantifying mammalian transcriptomes by RNA-Seq. Nature Methods 5(7):621-629.

Newall CA, Anderson LA, Phillipson JD (1996). Herbal medicines. A guide for health-care professionals. The Pharmaceutical Press, London pp 3-12.

Peer WA, Bandyopadhyay A, Blakeslee JJ, Makam SN, Chen RJ, Masson PH, Murphy AS (2004). Variation in expression and protein localization of the PIN family of auxin efflux facilitator proteins in flavonoid mutants with altered auxin transport in Arabidopsis thaliana. The Plant Cell 16(7):1898-1911.

Li P (2010). Bioinformatic analysis of flavanone 3-hydroxylase in plants. Journal of Anhui Agricultural Sciences 38(6):2817-2819.

Schilcher H, Imming P, Goeters S (2005). Active chemical constituents of Matricaria chamomilla L. syn. Chamomilla recutita (L.) Rauschert. Chamomile Industrial Profiles, Florida, Boca Raton pp 56-76.

Lee SS, Lee EM, An BC, Cho JY, Kim TH, Choi YO, Chung BY (2009). Isolation and characterization of flavanone 3hydroxylase genes from a Korean raspberry. Korean journal of horticultural science and technology 27(3):432440.

Shen G, Pang Y, Wu W, Deng Z, Zhao L, Cao Y, Tang K (2006). Cloning and characterization of a flavanone 3hydroxylase gene from Ginkgo biloba. Bioscience Reports 26(1):19-29.

Shen Q, Lu X, Yan T, Fu X, Lv Z, Zhang F, Tang K (2016). The jasmonate-responsive AaMYC2 transcription factor positively regulates artemisinin biosynthesis in Artemisia annua. New Phytologist 210(4):1269-1281.

Song Q, Xu F, Tao T, Liu X, Zhang W, Zhu L, Wang G (2015). Cloning and sequence analysis of a flavanone 3hydroxylase gene from Prunus persica (L.) Batsch. International Journal of Biosciences 7(5):136-145.

Stobiecki M, Kachlicki P (2006). Isolation and identification of flavonoids. The Science of Flavonoids, New York pp 4769.

Su S, Liu X, Pan G, Hou X, Zhang H, Yuan Y (2015). In vitro characterization of a (E)- $\beta$-farnesene synthase from Matricaria recutita L. and its up-regulation by methyl jasmonate. Gene 571(1):58-64.

Taylor LP, Grotewold E (2005). Flavonoids as developmental regulators. Current Opinion in Plant Biology 8(3):317323.

Xu Z, Cui G, Li C (2008). Cloning, sequence analysis and expression of flavanone 3-hydroxylase gene in turnip. Molecular Plant Breeding 6(4):787-792.

YanJ, Meng X, Xu F, Chang J (2016). Molecular cloning and sequence analysis of a phosphomevalonate kinase gene $(C n P M K)$ from Chamaemelum nobile. International Journal of Current Research in Biosciences and Plant Biology 3(10):157-162.

Zhang H, Zhao L, Wang J, Zheng L, Dang Z, Wang Y (2014). Cloning and functional analysis of two flavanone-3hydroxylase genes from Reaumuria trigyna. Acta Physiologiae Plantarum 36(5):1221-1229.

Zhang HL, Huang YS, Yang CX, Wu JY, Lu J, Zhang QT (2010). Molecular cloning and sequences analysis of flavanone 3-hydroxylase gene from Fagopyrum tataricum. Acta Botanica Boreali Occidentalia Sinica 30(3):447-452.

Zhao D, Tang W, Hao Z, Tao J (2015). Identification of flavonoids and expression of flavonoid biosynthetic genes in two coloured tree peony flowers. Biochemical and Biophysical Research Communications 459(3):450-456.

Zhao X, Zhang Q, Wang Z (2010). A review of the recent study progresses in anticancer activity of flavonoids. Journal of Northeast Agricultural University 41(4):133-138.

Zhou X, Yin H, Zhu Y, Li J (2015). Cloning and expression analysis of flavanone 3-hydroxylase gene CnF3H from Camellia nitidissima. Molecular Plant Breeding 13(9):2051-2057. 
OPEN ACCESS

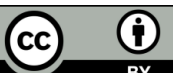

The journal offers free, immediate, and unrestricted access to peer-reviewed research and scholarly work. Users are allowed to read, download, copy, distribute, print, search, or link to the full texts of the articles, or use them for any other lawful purpose, without asking prior permission from the publisher or the author.

License - Articles published in Notulae Botanicae Horti Agrobotanici Cluj-Napoca are Open-Access, distributed under the terms and conditions of the Creative Commons Attribution (CC BY 4.0) License.

(C) Articles by the authors; UASVM, Cluj-Napoca, Romania. The journal allows the author(s) to hold the copyright/to retain publishing rights without restriction. 